\title{
CULTURA PHYSICA E VIDA AO AR LIVRE: A REINVENÇÃO DO LITORAL DE FORTALEZA (1920- 1940)
}

\author{
PHYSICAL CULTURE AND OUTDOOR LIFE: THE REINVENTION OF THE COAST \\ OF FORTALEZA (1920-1940)
}
CULTURA FÍSICA Y VIDA AL AIRE LIBRE: LA REINVENCIÓN DEL LITORAL DE FORTALEZA (1920-1940)

Nara Romero Montenegro*, Carmen Lúcia Soares*

Palavras chave:

História.

Esportes.

Natureza.
Keywords:

History.

Sports.

Nature.

Resumo: Importantes e inéditas transformações se operam no imenso litoral brasileiro nas primeiras décadas do século XX. Nosso estudo examina essas transformações tomando como delimitação geográfica o litoral de Fortaleza, as inúmeras atividades de divertimento e outras voltadas à educação e à saúde que ali se desenvolveram. Já nas décadas de 1920 e 1930 também surge ali nova arquitetura que recorta esse litoral com bangalôs, casas, comércios, clubes esportivos e recreativos. Discursos e práticas higienistas associados a um ideário de vida ao ar livre exortam a população não só a admirar o litoral, mas a usufruir de seus benefícios. $O$ presente artigo objetiva analisar a relação entre a reinvenção do ambiente litorâneo de Fortaleza e os discursos, cada vez mais frequentes, em torno de uma cultura physica. Em termos metodológicos, realizamos uma pesquisa documental que teve como fontes: jornais, revistas, textos literários, relatos de memorialistas e imagens do período.

Abstract: Important and unprecedented changes take place in the Brazilian coast during the first decades of the twentieth century. Our study examines these changes, focusing on the coast of Fortaleza, the numerous leisure activities that happened in that space as well as those oriented to education and health. A new architecture also appears in that space in the 1920s and 1930s, shaping the coast with bungalows, houses, commercial establishments as well as sport and recreational clubs. Hygienist discourses and practices associated with an outdoor lifestyle exhort people not only to admire the coast but also to enjoy its benefits. The present article analyzes the relationship between the reinvention of Fortaleza's coastal environment and the increasingly frequent discourses about a physical culture. As for methodology, we carried out a documentary research using the following sources: newspapers, magazines, literary texts, reports of memorialists and images from the period.

Palabras clave: Historia. Deportes. Naturaleza.
Resumen: Importantes e inéditas transformaciones se operan en el inmenso litoral brasileño en las primeras décadas del siglo XX. Nuestro estudio investiga esas transformaciones, tomando como marco geográfico el litoral de la ciudad de Fortaleza, en las numerosas actividades de ocio y otras dedicadas a la educación y a la salud que allí se desarrollaban. En las décadas de 1920 y 1930 surge allí una nueva arquitectura que recorta este litoral con bungalows, casas, comercios y clubes deportivos y recreativos. Discursos y prácticas higienistas, asociados a un ideal de vida al aire libre, incitan a la población a no solo admirar la costa, sino a disfrutar de sus beneficios. El objetivo de este artículo es analizar la relación entre la reinvención del ambiente costero de Fortaleza y los discursos, cada vez más frecuentes, sobre una cultura física. En términos metodológicos, realizamos una investigación documental con las siguientes fuentes: periódicos, revistas, textos literarios, relatos de memorialistas e imágenes del periodo.
*Universidade Estadual de Campinas. Campinas, SP, Brasil. E-mail: nararomerom @ hotmail.com; carmenls@unicamp.br

Recebido em: 14-12-2018 Aprovado em: 07-06-2019 Publicado em: 17-12-2019

DOI https://doi.org/10.22456/1982-8918.88925 (c) (1) () Licence 


\section{INTRODUÇÃO}

[...] o espectaculo sempre atrahente dos banhos de mar, em que os cavalheiros, as senhoras, as senhorinhas e as creanças, retroagindo aos tempos primevos, velando o tronco e exibindo pernas e braços, uns mais grossos, medios e roliços, outros mais finos, ossudos e angulosos, correm, ao ar livre, rolam na areia e mergulham nas aguas, mythologicamente, como Neptunos e Sereias. ${ }^{1}$

O espetáculo dos banhos de mar evocado na epígrafe apresenta narrativa pouco usual até a década de 1920 no litoral de Fortaleza, assim como em outras cidades brasileiras banhadas pelo Atlântico ${ }^{2}$. A praia não era ainda esse lugar sempre atraente, desenhado como adequado para uma vida ao ar livre, mergulhos nas águas salgadas e doces momentos de repouso ao sol. No caso de Fortaleza, definitivamente, até essa década, a praia não era um lugar de encontros para a maior parte dos habitantes da cidade. Declarar que a praia era vazia, inabitada, entretanto, seria um equívoco, pois comunidades de pescadores e estivadores já viviam ali. Ao intitular este artigo evitamos a expressão descoberta do litoral, pois tal escolha ocultaria certas tensões e conflitos pelos quais esse ambiente passou. Optamos, portanto, pelo termo reinvenção para chamar atenção para o deslocamento de sentido que se operou na praia.

No final do século XIX e começo do século XX, Fortaleza era uma cidade que parecia crescer de costas para o mar. Segundo Schramm (2001) e Matos (2009), a maioria de suas edificações urbanas não se localizava nas proximidades da praia, e as poucas existentes se restringiam ao atendimento de demandas sociais de parcelas desfavorecidas da população, como era caso da Santa Casa e da Cadeia Pública, ou, ainda, da Estação Ferroviária, construída com a fachada principal voltada para o sertão e de costas para o mar. A falta de apreço pelo litoral pode ser percebida, como indica Montenegro (2016; 2017), também em jornais, que até o começo do século XX referiam-se a esse ambiente de uma forma bastante negativa. A presença do mar e da praia nos jornais estava vinculada sobretudo à sujeira, através de notas muito críticas em relação ao estado degradado do litoral. Referiam-se, também, aos trabalhadores desse lugar, pescadores e estivadores, assim como às notícias de afogamentos.

É na década de 1920 que a praia começa a ter seus usos transformados e ser frequentada por parcelas da elite fortalezense; inscreviam-se, naquele momento, outras práticas e representações do lugar, cujo objetivo não era mais aquele voltado ao trabalho; concomitantemente, este período acolhe as primeiras edificações específicas de sua orla destinadas ao repouso e à contemplação — casas e bangalôs. De um lugar até então noticiado como insalubre e sem atrativos pelos jornais e revistas, o período assinalado dá lugar a notícias e reportagens que insistem nas atrações praianas: restaurantes à beira-mar dividem as páginas com episódios inusitados, como o pouso de um avião, ou, ainda, uma campanha, em 1925, para modificar o nome da praia, até então conhecida por Praia do Peixe, para Praia de Iracema.

Forma-se um novo discurso em torno do litoral, embasado principalmente por conselhos e prescrições médico-higienistas, que atribuíam um valor inédito à vida ao ar livre. Paralelamente, e em consonância com essa ideia, o estímulo à prática de exercícios físicos, esportes e ginásticas, isto é, elementos do que se pode chamar de cultura physica, torna-se

1 O Chefe de Polícia e o banho de mar. Ceará Illustrado. Fortaleza, n. 52, 05/07/1925.

2 Ver Freitas (2014); O’Donnell (2013); Schossler (2013); Terra (2016). 
corriqueiro nas fontes. Esse novo discurso assinala, entre outros aspectos, uma nova relação com a natureza e uma insistência nos benefícios de uma vida ao ar livre.

Ao evocarmos elementos de uma cultura physica, apoiamo-nos nos estudos e pesquisas realizados por Kirk (1999; 2010), Scharagrodsky (2014; 2017) e Reggiani e Scharagrodsky (2016) no que se refere a esse conceito, o qual fornece elementos para pensar uma complexa rede de significações. Cultura physica, assim, é um conceito que permite aproximar temas e problemas que ultrapassam a dimensão biológica, frequentemente evocada para se referir às ginásticas, aos esportes, às inúmeras e diversificadas performances corporais - esportivas ou não - e, ainda, às múltiplas práticas recreativas junto à natureza.

Scharagrodsky (2014; 2017) e Reggiani; e Scharagrodsky (2016) analisam 0 conceito cultura física em sua íntima relação e implicação com sistemas de exercícios físicos consolidados ao longo do século XIX, modernos em sua concepção, buscando simetria corporal, racionalização energética, ou, ainda, um completo redirecionamento de gestos e posturas, conforme analisou Vigarello (1978) naquilo que denominou de "poderes pedagógicos", ou seja, formas de intervenção no corpo. Aqui cabe sublinhar que as inúmeras práticas sistematizadas e institucionalizadas, como as ginásticas, as danças, os jogos e os esportes, expressaram crenças, conhecimentos, saberes e práticas individuais e sociais mais amplas e efetivamente constituíram o que os autores denominam de "cultura física". Conforme os estudos e pesquisas de Reggiani e Scharagrodsky (2016), o conceito permite operar de forma mais ampla com discursos e práticas centradas no corpo a partir de abordagens com fins estéticos, recreativos, científicos, econômicos, bem como aproximar-se dos universos da literatura, das artes plásticas e cênicas, da moda e da publicidade, das ginásticas, da recreação e dos esportes. Permite, também, operar com discursos e práticas no âmbito da medicina e da sexologia, do trabalho e da ergonomia.

Em nosso artigo, o conceito foi mobilizado para indagar a cultura physica no litoral de Fortaleza, entre 1920 e 1940, portanto, a experiência moderna daquela cidade. No período em questão, a cidade teve como elementos centrais o debate, as prescrições e os conselhos que giravam em torno de disputas sobre o corpo, a saúde, a educação, os divertimentos e, sobretudo, os lugares para sua realização, como foi o caso da reinvenção da praia. Assim, sempre que nos referirmos a esse conceito estaremos apoiadas nos autores aqui citados.

O problema central deste artigo é a transformação que se operou no litoral da cidade de Fortaleza a partir, sobretudo, da década de 1920. Nesse período destacamos a possível relação entre uma cultura physica em emergência e a reinvenção de um espaço ao ar livre, cujos elementos até então preteridos passaram a ser tão estimados e valorizados. Nosso objetivo, portanto, é analisar a relação entre a reinvenção do ambiente litorâneo da cidade de Fortaleza e os discursos, cada vez mais frequentes, em torno de uma cultura physica.

Em termos metodológicos, trata-se aqui de uma pesquisa documental que teve como fontes jornais e revistas (Jornal do Ceará, entre os anos de 1904 e 19113; O Povo, entre 1928 e1940; Correio do Ceará, entre 1927 e 1946; O Nordeste, entre 1922 e 1946; e a revista Ceará Illustrado, de 1924 e 1925). A análise metodológica de nossas fontes impressas apoia-se nos estudos de Luca (2006), que destacam a importância de atentar aos discursos produzidos pela

3 Embora o recorte temporal desta pesquisa indique as décadas de 1920 até 1940, a presença do Jornal do Ceará entre os anos 1904 e 1911 nos ajuda a entender alguns sentidos atribuídos ao espaço praiano antes de transformar-se num atrativo de sociabilidade, divertimento, saúde e educação, reconhecido pela maior parte da população. 
imprensa, tendo em vista suas motivações, temas e linguagens escolhidos a fim de atingir um público específico, bem como o diálogo com os outros periódicos do período. Compõe ainda nosso conjunto de fontes imagens encontradas na imprensa do período, no Almanach do Estado do Ceará e no Arquivo Nirez, bem como crônicas e livro de memorialistas.

\section{A EMERGÊNCIA DA CULTURA PHYSICA EM FORTALEZA}

$\mathrm{Na}$ aurora do século XX, a cidade de Fortaleza passa por diversas tentativas de modernização de sua estrutura urbana e de seus costumes, vivendo sua chamada belle époque. Este período é caracterizado pela:

[...] apregoada necessidade de torná-la um centro desenvolvido e civilizado, um movimento considerável de discursos e práticas emergiu e procurou - sobretudo através de estratégias embelezadoras, saneadoras e higienistas - ordenar seu espaço e disciplinar sua população (PONTE, 1993, p.15).

A cidade civilizada, entretanto, era uma utopia. Junto à nova ordem urbana que insistia em instalar-se, ocorre o crescimento desordenado de sua população, o que acentua os malefícios das aglomerações urbanas e as consequências para a vida citadina. No final do século XIX e início do século XX, o estado do Ceará sofre com as constantes secas, e Fortaleza, capital do estado, torna-se o destino de um número significativo de retirantes que, de modo desordenado, ocupam largos espaços da cidade (NEVES, 2014; PONTE, 1993).

É, portanto, nessa situação de calamidade que muitas denúncias de espaços públicos insalubres, hábitos higiênicos e cuidados com o corpo considerados inadequados são publicados em páginas de revistas e jornais, num esforço evidente de fazer a população fortalezense afastá-los do seu cotidiano.

Em abril de 1905, o Jornal do Ceará denuncia a epidemia de Dysenteria que assola a capital, associando-a aos hábitos alimentares e de higiene:

A epidemia actual é apenas uma crise de estado mórbido que lavra insidioso no seio do organismo de Fortaleza, e que se complica dia a dia. A causa primaria das febres, grippes, diarrhéas etc, está nas fossas fixas, na água impotavel que bebemos, no leite falsificado que é fornecido ás creanças, nas fructas verdes vendidas na feira, no lixo que se accumula na praia ou nos quintaes ${ }^{4}$

Ainda em 1907, o lixo era acumulado nos arredores da praia, e o Jornal do Ceará, no mesmo ano, assim se exprime sobre o tema:

Nada mais triste para quem chega de fora ou tenha de desembarcar em nosso porto do que a impressão que causa aquelle monturo enorme que se estende em larga area desde o portão da cadeia publica á linha férrea do ramal da praia. ${ }^{5}$

O medo estava em todos os lugares. Não só nos corpos dos miseráveis, mas no porto, no ar, na água, nas edificações, nas fábricas - na cidade, enfim. O comércio e a publicidade, pertinentemente, ao perceber esse cenário, iniciam campanhas dos mais diversos produtos redentores dos males que assolam a nova ordem urbana.

Os jornais travam incansavelmente um combate contra o álcool, a mendicância, além de todas as moléstias da nova vida urbana, desde a saúde dos pulmões, os reumatismos, a anemia, até os cuidados com a estética do corpo, os cabelos brancos, os seios e o mau hálito. 
O cuidado de si torna-se, dessa forma, um imperativo na imprensa. A partir, sobretudo, da década de 1920, o estímulo à cultura physica passa a integrar os discursos que têm como função desenvolver uma reação à nova ordem urbana. Isto porque viver na cidade tornarase difícil, pois seus novos ritmos exigiam disposições em que não podia faltar vigor físico e disciplina.

Assim, inúmeras ideias, prescrições e conselhos passam a circular na imprensa da capital no que concerne à saúde e sua preservação. É o caso do material elaborado pelo professor de ginástica Enéas Campello, que consiste em aparelhos de ginástica e instruções impressas, e que passa a ser comercializado na Livraria Ribeiro na capital. Nas imagens (Fig.1 e Fig.2) que seguem transparece o vigor, a retidão e a seriedade, qualidades exigidas para aqueles que estão determinados a alcançar seus objetivos.

Figura 1 - Força, Belleza e Saúde

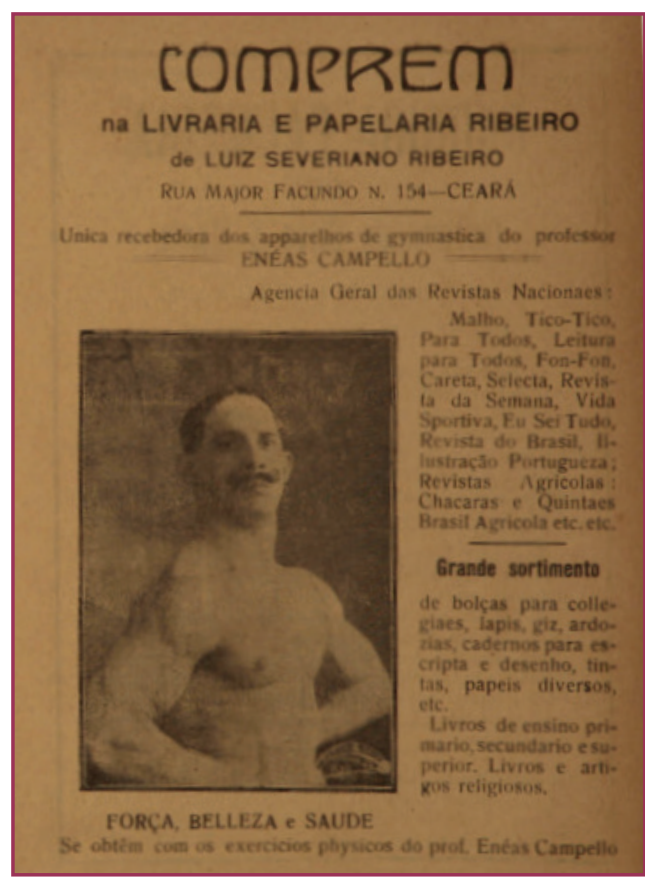

Fonte: Almanach do Estado do Ceará de 1920
Figura 2 - Gymnastica de Quarto

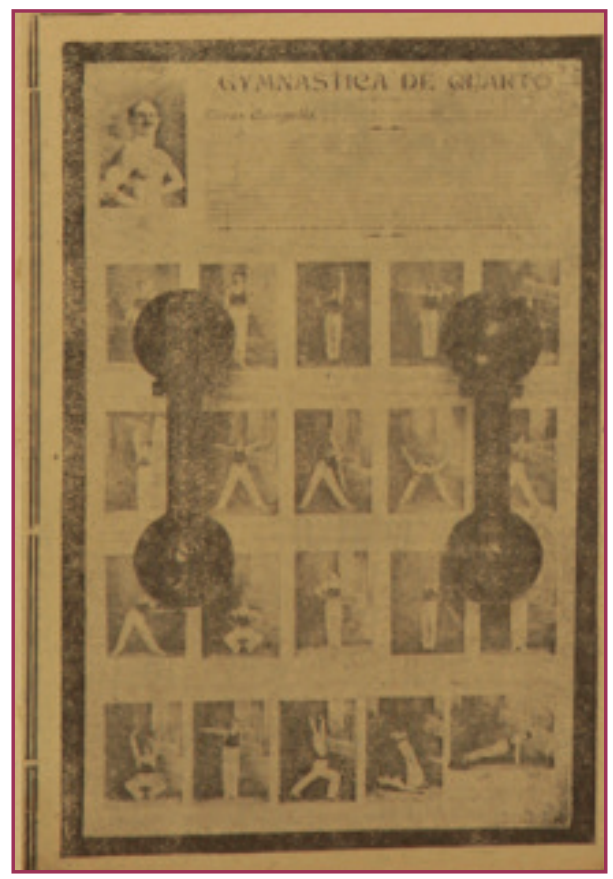

Fonte: Almanach do Estado do Ceará de 1921

Em uma das cartilhas do professor Enéas Campello (Fig.2), publicada no Almanach do Estado do Ceará de 1921, os exercícios aparecem ordenadamente, oferecendo aos seus leitores uma diversidade de métodos e de autores, mas assinalando sua preferência pela ginástica sueca. Ele também elogia o uso dos halteres, que, segundo sua análise, é "proporcional á consistência de cada individuo" e tem Ihe permitido colher "resultados suprehendentes". Insiste, ainda, na ideia de serem os aparelhos "adaptaveis a qualquer sexo e a qualquer idade, produzindo um desenvolvimento harmonioso em todo o organismo".

Enéas Campello simboliza bem um novo tipo de profissional demandado pela emergência da vida urbana: o professor de gynastica. Aliado ao conhecimento médico, ele detém os saberes relativos aos exercícios corporais, tão necessários à manutenção da saúde e disposição geral do indivíduo.

"A cultura physica a serviço da belleza e da força: conserve sua vitalidade" é o título de um texto publicado pela revista de variedades Ceará Illustrado ${ }^{6}$. A suposta autora 
de nome aparentemente estrangeiro, Madaleine Taylor, escreve sobre a importância dos exercícios físicos para a disposição, a vida ativa e produtiva e, em suas publicações, descreve detalhadamente o modo de execução de um exercício.

Pouco a pouco, a ginástica conquista espaço significativo de atenção não apenas para os adultos, mas também para as crianças, à medida que passa a fazer parte do currículo obrigatório das escolas públicas. A inclusão da ginástica no currículo escolar expressava um contexto mais amplo da reforma do ensino, localizada a princípio na Escola Normal e realizada pelo pedagogo paulista Lourenço Filho, em 1922, a convite do governo cearense (ALMEIDA; LIMA, 2009).

Conforme podemos ler em artigo publicado no Almanach do Estado do Ceará, havia "uma profunda crise do ensino primario no Ceará", daí a necessidade de mudanças e o convite feito a Lourenço Filho para o cargo administrativo. Com o poder que o cargo lhe permitia, ele pôde realizar transformações significativas no ensino, como a reorganização da Escola Normal, com uma mudança curricular em que foram acrescentadas disciplinas como "Anatomia e Fisiologia Humana", "Higiene" e "Ginástica". Outras reformas administrativas que fundavam novos cargos e cadastros escolares para controle de dados relativos à educação também aconteceram, além de reformas no espaço físico da escola, que agora deveria ganhar novas práticas escolares, entre elas, a ginástica ao ar livre.

Figura 3 - Aula de Ginástica ao ar livre

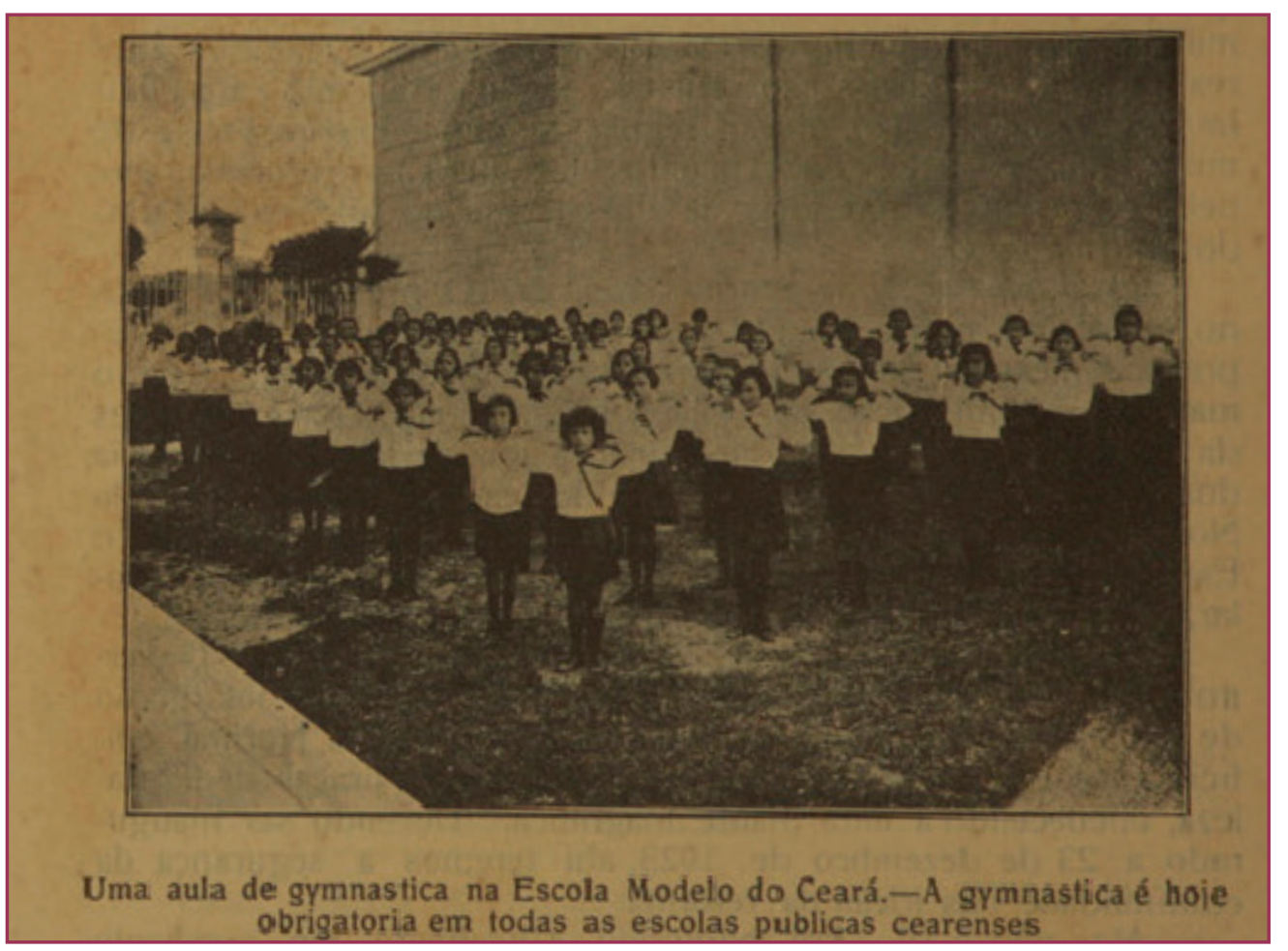

Fonte: Almanach do Estado do Ceará de 1924

Além dos adultos em geral e crianças, as mulheres pareciam ser uma preocupação à parte, pois acreditava-se à época que sua natureza era especificamente frágil, crença que começa timidamente a ser transformada ao longo da primeira metade do século XX. Alguns indícios dessa transformação podem ser verificados na pesquisa que realizou Luciana de

7 Almanach do estado do Ceará. Fortaleza, 1922, p.365. 
Almeida (2016) sobre a invenção do corpo feminino em Fortaleza. Nesse trabalho, a autora se debruçou sobre um extenso conjunto de fontes em que as imagens das mulheres, em especial nas revistas de variedades e anúncios, aparecem, já no início dos anos de 1920, com agilidade e leveza:

A imagem da feminilidade é revista: a mulher inerte, robusta, flácida e arredondada é sucedida pela jovem ágil e esguia que encarna a propensão 'natural' por atividades físicas. 0 movimento se integra ao ideal do corpo ativo, articulando beleza, leveza, saúde e dinamismo (ALMEIDA, 2016, p.180).

Em meio a essa tendência, na década de 1930, tem-se inclusive a fundação de um Sport Club Feminino para "alumnas de qualquer estabelecimento de instrucção ou de curso particular", tendo como objetivo "o desenvolvimento da cultura physica da mulher, por meio do volley-boll, do tennis, do criquet, do basquet-ball, de excursões campestres, exercícios de tiro ao alvo, etc."

Uma cultura physica parece instalar-se na capital, num contexto em que práticas de exercícios físicos e esportes modernos vão conquistando espaço na vida cotidiana de parte dos habitantes da cidade.

Foi em 1913 que, menino, travei conhecimento, por acaso, com o então chamado esporte bretão. E empoleirado na arquibancada natural e excepcional da Avenida Caio Prado, vi aquele bando de homens correndo atrás de uma bola de couro. Devia ser treino. Não havia uniformes e eu mesmo, sem ter a quem perguntar, não entendia bem o jogo. De quando em vez me parecia confuso (ALENCAR, 1980, p.58).

Conforme as impressões do memorialista que assiste incrédulo a um jogo que mal compreende, é possível inferir que, no período aqui recortado para este artigo, o esporte começa a ganhar espaço e passa a constituir a vida urbana e moderna, passa a ser visto como signo de saúde e vigor para homens, mulheres e crianças.

\section{EXORTAÇÃO DA VIDA AO AR LIVRE}

Paralelamente à emergência da cultura physica, discursos que estimulam a busca por uma vida ao ar livre também são encontrados nas fontes, muitas vezes associados à prática de exercícios físicos e de esportes. Essa combinação é concebida como capaz de dar mais vitalidade ao indivíduo, aparecendo quase como indispensável para a vida moderna:

Procure viver a maior parte do seu tempo ao ar livre. Um sport que the traga ao ar livre faz uma grande differença na disposição do individuo. E' outra a sua attitude na vida. E se a pessoa não póde de fórma alguma, se enthusiasmar por qualquer dos tantos sports conhecidos, sem duvida alguma, póde dedicar uma certa parte do seu dia a simplesmente andar, a correr, a brincar ao ar livre. São sports que fazem um grande bem ao corpo humano. ${ }^{9}$

Ideais acerca da importância do esporte ser realizado ao ar livre circulam em discursos médico higienistas, boletins, jornais e revistas de variedades que, paralelamente, acolhem uma gama imensa de atividades como caminhadas, corridas ou até simples brincadeiras. $\mathrm{O}$ que parece ser imperativo nas fontes pode ser lido nesta frase: "Procure viver a maior parte do seu tempo ao ar livre"10.

\footnotetext{
8 Sport Club Estudantal Feminino. Correio do Ceará. Fortaleza, 28/07/1930.

9 A cultura physica a serviço da belleza e da força, revista Ceará Illustrado. Fortaleza, n.27, 11/01/1925.

10 A cultura physica a serviço da belleza e da força, revista Ceará Illustrado. Fortaleza, n.27, 11/01/1925
} 
Em 1930, o Correio do Ceará chega mesmo a publicar as Regras da Saúde ${ }^{11}$, que consistem em 16 itens que constituem uma lista de hábitos referentes ao corpo, ao cuidado de si, mas, também, a uma natureza benéfica, na qual esses hábitos deveriam ser internalizados, pois eram questão de saúde pública. Adquirir um novo hábito ou livrar-se de um já assimilado teria o potencial de alavancar uma sociedade forte, saudável e civilizada. Na lista, chamamos atenção para dois itens: "6ํ- Fazer exercício physico antes do almoço"; e "10ำ- Fazer exercícios physicos todos os dias ao ar livre". É em meio a recomendações de higiene em geral (limpeza, alimentação, descanso) que os exercícios físicos e os esportes ganham espaço, desde que estejam conformes às prescrições. Trata-se não apenas de praticar exercícios físicos, mas de fazê-lo em horário e local indicados, preferencialmente, ao ar livre.

Nas escolas também é possível observar a importância que a vida ao ar livre adquire (Fig.4). Na descrição do Recreatório Infantil, que recebia crianças de Educação pré-primária, a sua instalação chama atenção. "O Recreatorio se acha instalado ao ar livre. Um lindo caramanchão serve-lhe de vestíbulo. Penetrando a impressão é de encantar. "12.

Figura 4 - Descanso ao ar livre

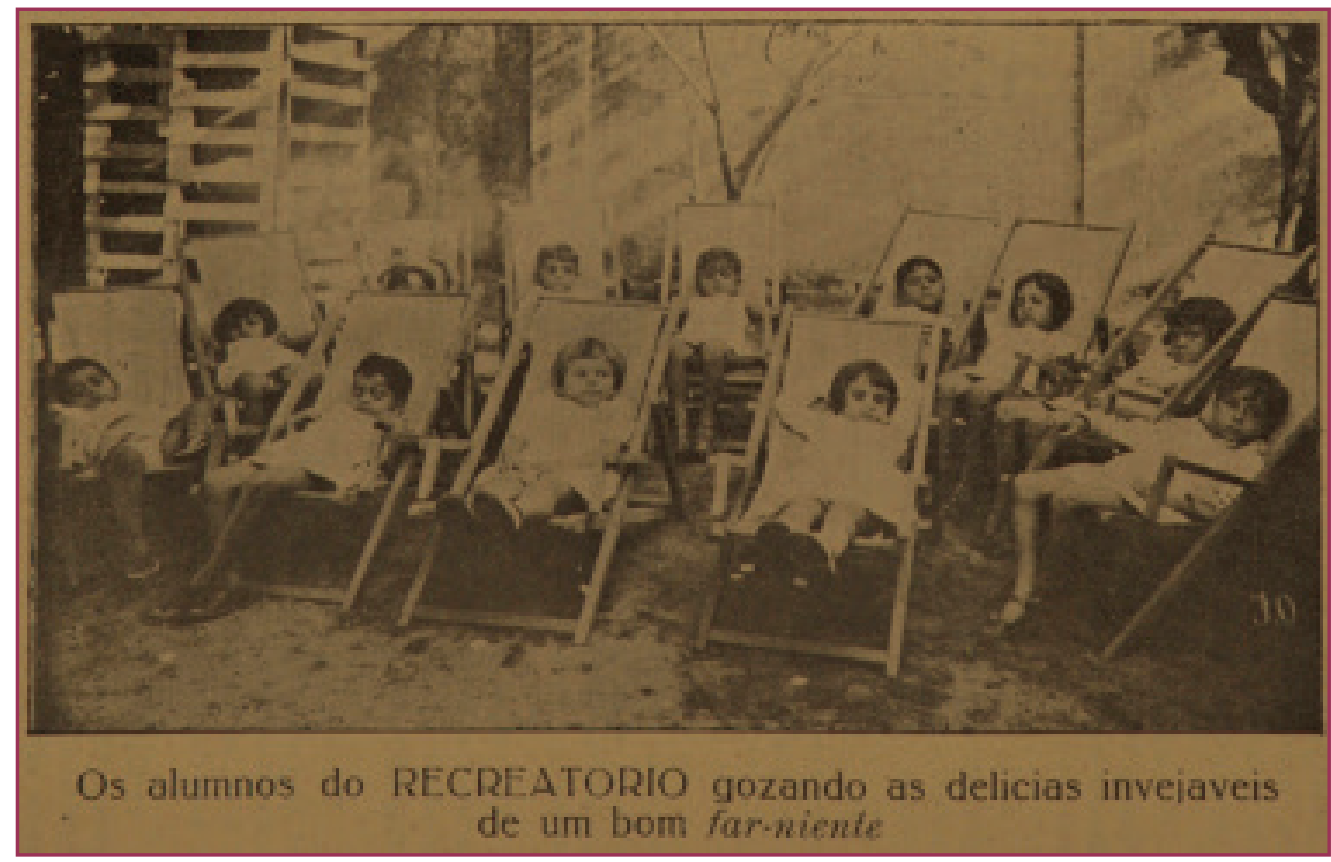

Fonte: Almanach do Estado do Ceará de 1935

O caramanchão, típica construção de jardins, já prepara para o cenário agradável que se encontra no interior, a exemplo da figura. A serviço da prática pedagógica, a atenção com os jardins também se faz presente:

As crianças, em um ambiente de intensa alegria, trabalham divertidamente. Util e agradavel se conjugam ali, harmonicamente. Os garotos cultivam seus jardins proprios e os cultivam com gosto. Uns trazem os carrinhos de areia, outros manejam pequenos instrumentos. Os mais habeis auxiliam os menos dotados nesse mister: é um ambiente de franca colaboração, onde os garotos desde logo se habituam á solidariedade, primeiro passo para a vida social. Aliás, tudo, no Recreatório Infantil, se faz em vista de um fim. ${ }^{13}$

11 Regras da Saúde, Correio do Ceará, Fortaleza, 11/07/1930.

12 Almanach do estado do Ceará. Fortaleza, 1935, p.266.

13 Almanach do estado do Ceará. Fortaleza, 1935, p.266. 
O lugar que a natureza e a exortação à vida ao ar livre passam a ocupar no ensino é bastante central, tornando-se instrumentos indispensáveis de boa educação. "O mestre, o livro, o contacto com a natureza do meio em que vive, auxiliá-la-ão grandemente a cultivar o seu cerebro e a desenvolver a sua inteligencia." ${ }^{14}$, escreve uma aluna do $4^{\circ}$ ano do Grupo Escolar do Benfica em 1931. Nesse trecho, na visão da aluna, o contacto com a natureza aparece ao lado do mestre e do livro, o que significa bastante legitimidade e até um caráter educativo para a natureza. É, portanto, uma transformação de sensibilidades em relação à natureza e à vida ao ar livre, conjuntamente com o crescimento e urbanização da cidade no começo do século $X X$.

\section{A REDERSCOBERTA DO LITORAL E ESPORTES NÁUTICOS}

Tendo em vista o cenário em que a cultura physica está em evidência, e o incentivo da vida ao ar livre aparece em discursos a respeito das várias esferas da vida, o litoral começa a ser visto de novas formas. Embora algumas fontes não o citem diretamente, uma nova disposição com espaços abertos, ao ar livre, parece se formar. A valorização da cultura physica e a busca pelo ar livre emergem como discursos que estão em consonância frente a uma nova urbanização e fazem da praia um lugar prestigioso.

A partir da década de 1920 é notório que o interesse pela praia passa a ser difundido. Agora não só os pescadores, estivadores e travessas crianças o buscam, mas, também, e cada vez mais, os grupos sociais favorecidos, as elites. Não é por acaso que é nessa década que surgem as primeiras casas requintadas e bangalôs na beira da praia, e até um cinema, chamado Beira-Mar, é construído (SCHRAMM, 2001).

Éemmeio ao entusiasmo de novos grupos sociais pelo litoral, manifesto necessariamente por um distanciamento do seu sentido anterior, que a cronista Adília de Albuquerque Morais sugere, em 1924, a construção de um monumento em homenagem a Iracema, personagem da célebre obra de José de Alencar, escritor cearense. Seria esse o começo institucional de um deslocamento de sentido que o litoral fortalezense assistiria.

No ano seguinte, inicia-se uma campanha - que terminaria por ser bem-sucedida - para a mudança do nome da Praia do Peixe para Praia de Iracema, liderada pela mesma jornalista e apoiada por Júlia Galeno, poetisa filha de Juvenal Galeno; Demócrito Rocha, jornalista que viria a ser o fundador do jornal O Povo em 1928; Júlio Maciel, poeta prestigiado; Beni Carvalho, advogado e político; e Gastão Justa, também jornalista.

O conjunto dos líderes da campanha, intelectuais e profissionais liberais, parecia se identificar mais com a elegância, poesia e alegoria do título Praia de Iracema, uma vez que Praia do Peixe soava, para esse grupo, assaz vulgar:

Aquelle recanto, aquella marinha cearense, perde muito de sua belleza com esse nome de Praia do Peixe, nome que exhala tanta maresia e tão intenso fartum de visceras de garôpa expostas ao sol, á vista enbiçosa dos urubús malandros.

Foi, por isso, muito feliz a Idea daquelles moços -Idea abralada de pronpto pelas familias que habitam a Praia do Peixe - de atirar-se fóra, lá para longe, esse nome tão prosaico e que parece dizer uma tolice - que as demaes praias não têm peixe...

-PRAIA DE IRACEMA, sim!

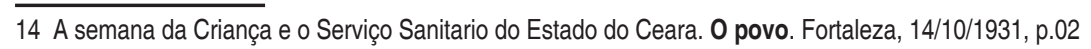


Praia de Iracema, da «virgem que tinha os labios de mel e os cabellos mais negros que as azas da graúna»...

Vença a idéa feliz! ${ }^{15}$

Como indica Silva Filho (2001, p.56): "Pensar e enunciar os lugares da cidade, e nela se orientar por outros nomes, implica apropriar-se de seus territórios e dar-lhes significado, imprimir no traçado urbano as marcas subjetivas da experiência cotidiana (...)". Muito mais que modificar um nome, há a intenção de inculcar-lhe um novo sentido em sintonia com os interesses modernos e capaz de admitir novas práticas:

Parece que, com a mudança do feio nome de Praia do Peixe, a mais formosa marinha cearense, encanto da nossa sociedade elegante, está adquerindo um desusado movimento nestes ultimos dias.

Ranchos de namorados felizes e sorridentes confundem os seus arrulhos com 0 marulho das ondas: automóveis businam: ouvem-se risadas e canções.

Consta mesmo que alguns poetas indigenas tencionam abrir nesta revista um concurso de sonetos sobre as maravilhosas perspectivas que aquella praia nos suggestiona.

Influencia do novo nome... ${ }^{16}$

Dessas novas práticas, cabe destacar, no trecho citado, os encontros de casais e as risadas e canções como evidências de que a praia agora era reinventada e tornou-se um lugar de encontro que se constituiu na cidade como um espaço romântico, cenário de novas sociabilidades. Os automóveis e suas buzinas formam o desenho de uma praia moderna, próxima ao centro urbano e palco de novas práticas e representações.

Um novo cenário se desenha na cidade: a cultura physica emerge, e a frequentação do litoral, juntamente com o estímulo de um ideário de vida ao ar livre, estão em voga. Nessas circunstâncias, esportes náuticos e banhos de mar passam a ser atividades da vida cotidiana de parte de sua população.

Cada vez mais, notícias de afogamentos aparecem em jornais. Em 1929, inclusive, é instituído pela primeira vez na cidade um posto de socorro aos banhistas. Embora afogamentos sempre tenham ocorrido, é só na década de 1920 que se tem uma preocupação pública com a prática de banhos de mar e a segurança dos banhistas, o que, em alguma medida, indica um novo patamar de legitimidade de tal prática.

No mesmo ano acontece a fundação do primeiro clube à beira-mar da cidade. 0 Náutico Athletico Club, que já nasce "com um quadro bem avultado de socios"17 e, como diz 0 próprio nome, tem por compromisso o desenvolvimento do esporte cearense, visando "tornar a mocidade forte e sadia"18.

Como se pode ver na imagem (Fig.5), inicialmente o Náutico possuía uma estrutura bastante simples. Rodeado de jangadas e coqueiros, sem, aparentemente, nenhuma casa mais sofisticada em volta, o local escolhido para a sede era rústico. No entanto, embora tivesse aparência modesta, na década seguinte, 1930, o clube passa a organizar grandes provas de natação na Praia de Iracema. Geralmente eram provas de 5.000 metros ou 10.000 metros de distância, que tinham dezenas de inscritos e ocorriam pelo menos uma vez ao ano. Os jornais

15 Ceará Illustrado. Fortaleza, n. 51, 28/06/1925.

16 Praia de Iracema. Ceará Illustrado. Fortaleza, n.52, 05/07/1925. 
demonstravam grande entusiasmo com o advento desse esporte. As notícias nos dias próximos ao da prova costumavam ser grandes e tinham manchetes como: "Desafio para uma prova de natação de 10.000 metros" (1933) ${ }^{19}$, "Hoje, a sensacional prova do Campeonato Cearense de Natação" (1937) $)^{20}$ "Grande prova de natação" (1939)

Figura 5 - Primeira sede do Clube Náutico (s.d.)

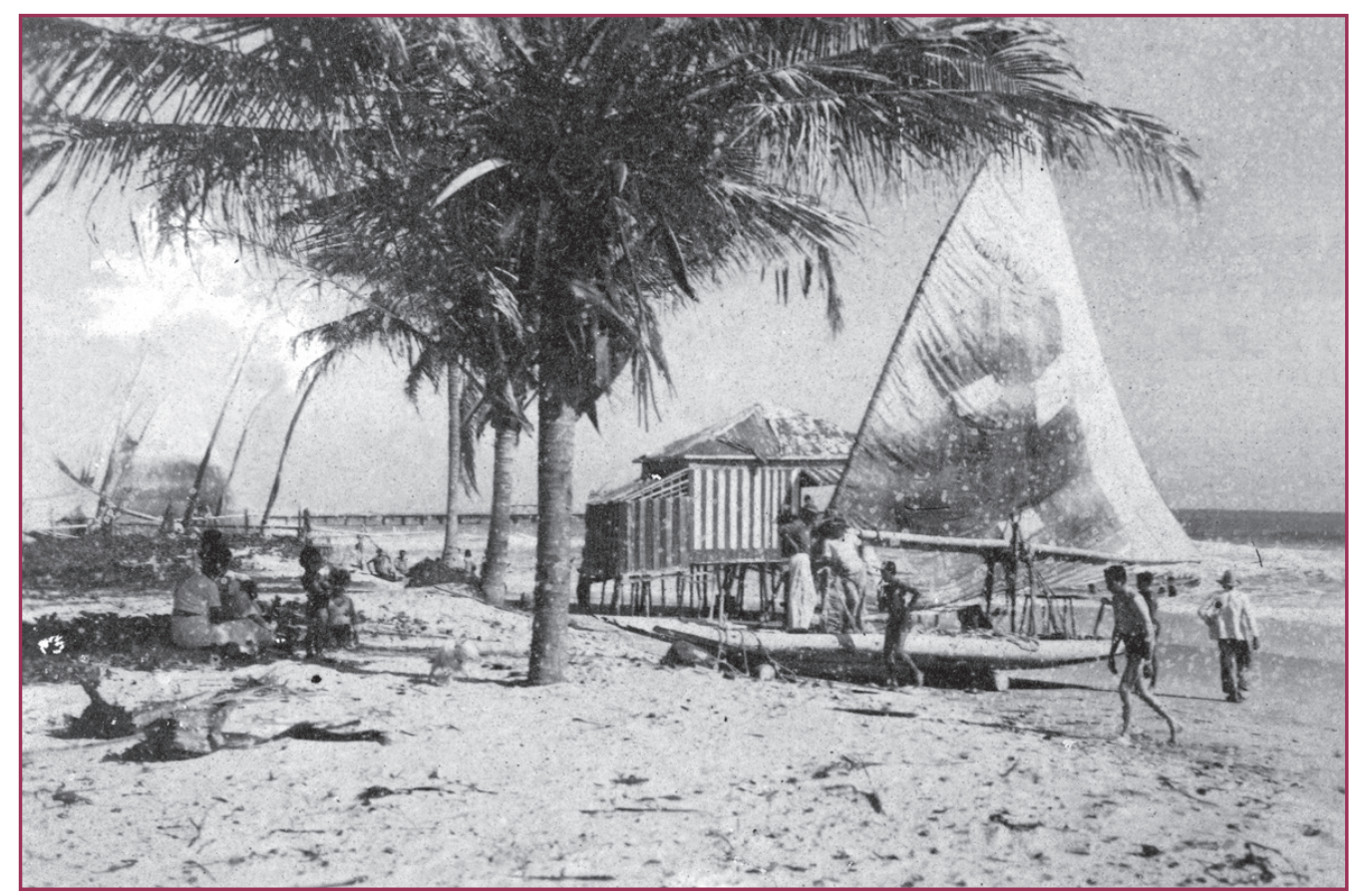

Fonte: Arquivo Nirez - Fortaleza

Em 1939, inclusive, tem-se pela primeira vez a participação oficial de uma mulher nas provas, segundo o jornal $O$ Nordeste: "A prova foi disputada por cinquenta e um candidatos, entre os quais a jovem conterranea, Irene Ribeiro, a primeira mulher, que, no Ceará, participa de um certame dessa natureza"22.

Na década de 1940, os desafios e as provas de nado vão se consolidando, culminando naquelas mais bem estruturadas que passaram a ser chamadas de "Prova Heroica". Segundo o jornal Correio do Ceará, "A Heroica é a maior prova de natação que se realiza em todo 0 país!"23. Considerada uma prova de longa distância, exaltava-se a braveza do povo cearense: "A peleja dos 5.000 metros é uma verdadeira luta de titans. Dela somente participam nadadores de raça e de tempera"24. Todas as provas contaram com pelo menos 50 inscritos, inclusive atletas de outras cidades.

Como se pode ver na imagem (Fig.6), as provas extrapolavam o envolvimento de competidores, torcedores e organizadores. Foram eventos prestigiados na cidade, em que se reuniram diferentes grupos sociais, conferindo, portanto, à praia formas inéditas de sociabilidade.

\footnotetext{
19 Desafio para uma prova de natação de 10.000 metros. Correio do Ceará, 03/04/1933, p.6.

20 "Hoje, a sensacional prova do Campeonato Cearense de Natação. Correio do Ceará, 19/12/1937, p.11

21 Grande prova de natação. 0 Nordeste, 12/08/1939, p.4.

22 Fortaleza empolga pelos desportos. 0 Nordeste, 14/08/1939, p.8.

23 A Heroica é a maior...Correio do Ceará, 21/02/1946, p.3

24 Bi-Campeão da Prova Heroica. Correio do Ceará, 02/03/1942, p.8
} 
Assim narra o memorialista Aluísio Girão $(1998$, p.20) a sua participação desinteressada em uma Prova Heróica: "Mesmo assim, eu, que nem sempre admiro as multidões, me confundi com a massa e fiz o 'footing' com aquele mundão de gente alegre, gozando as delícias deste ardentíssimo e amantíssimo sol cearense."

Figura 6 - VI Prova Heróica de 1945

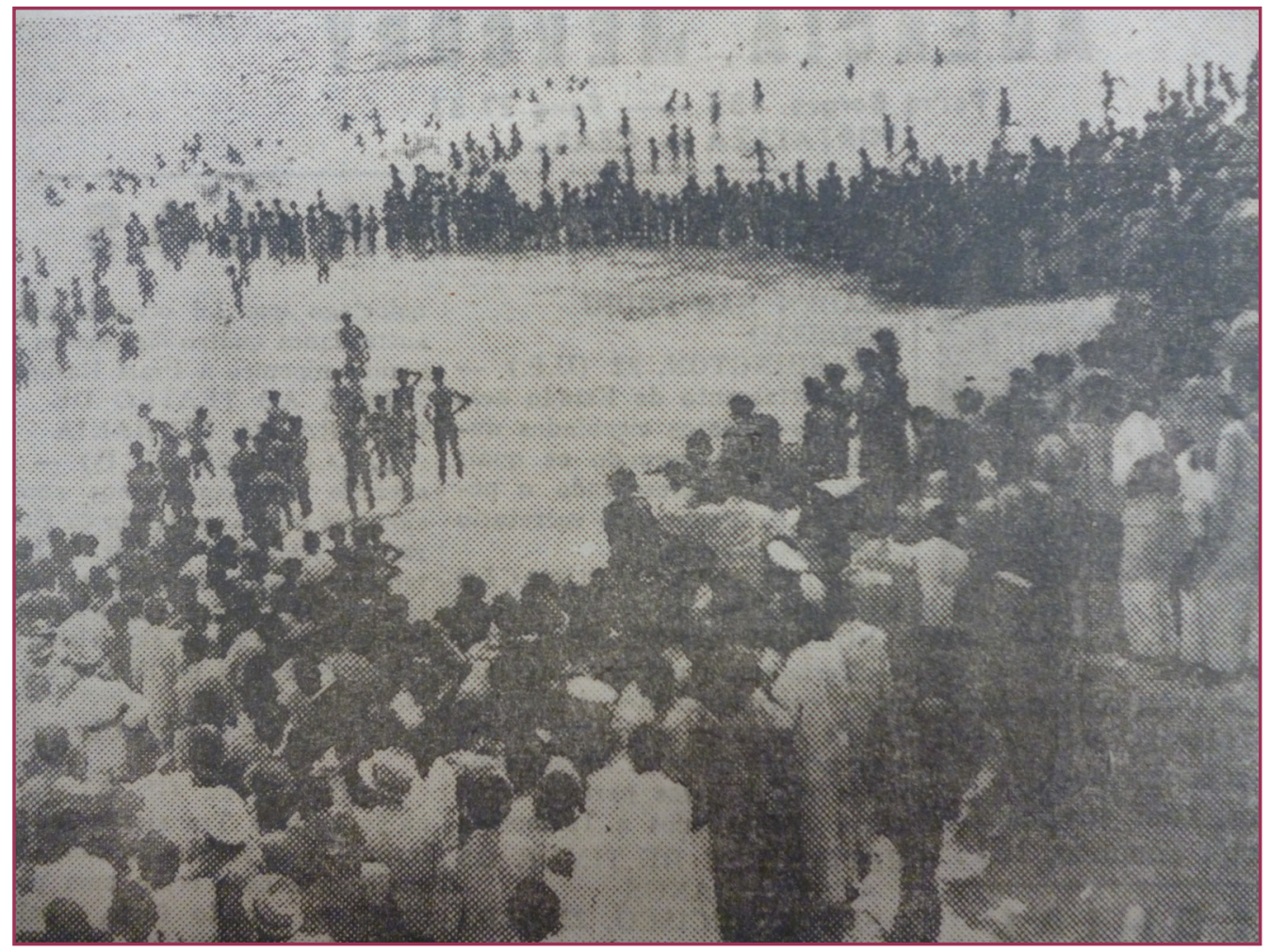

Fonte: Correio do Ceará, 23 de março de 1946, p.6

\section{CONSIDERAÇÕES FINAIS}

A praia da cidade de Fortaleza, assim como as de outras cidades litorâneas do Brasil, foi cenário de um deslocamento de sentido. Habitada inicialmente por indígenas e ribeirinhos, ela teve suas principais atividades voltadas ao trabalho, seja com a pesca, seja com o porto mais amplamente. A partir da década de 1920, o litoral começa a ganhar outro sentido, especialmente aquele dado por novas sensibilidades em relação à vida ao ar livre, tornando-se pouco a pouco um espaço de encontro e divertimento. Trata-se aqui de uma clara mudança de sentido que se operou no litoral fortalezense e que, contudo, não pode ser atribuída unicamente a uma explicação relativa ao crescimento urbano da cidade. Nota-se que nesse período a busca por bairros mais afastados do centro foi intensa. Uma das razões apontadas era o fato de que o centro da cidade se tornava cada vez mais populoso e popular, sendo essa uma interpretação largamente presente em livros que tratam da historiografia da cidade. Há, nessa interpretação, um predomínio de uma leitura socioeconômica que, mesmo sendo possível, nos parece insuficiente para explicar a reinvenção do litoral.

Neste artigo examinamos alguns discursos que ocuparam um lugar importante na mudança de sensibilidade, nas mentalidades e nas práticas da época. Em especial nos interessou o aparecimento de um discurso médico e higienista em aliança com o discurso educacional. São 
os preceitos médicos que elegem um novo lugar para a cultura physica, exaltando-a com poderes relativos à educação, à saúde e à moral. Paralelamente temos a emergência de novas relações com a natureza frente à vida urbana e moderna em franca ascensão.

A reinvenção do litoral de Fortaleza insere-se em um cenário complexo de crescimento urbano, intensificação da legitimidade do discurso médico e busca por uma natureza como refúgio, controlada e domesticada. Os discursos em torno da cultura physica e a reinvenção do litoral ocorrem conjuntamente e em consonância. Ao mesmo tempo em que a população cearense passa a buscar a praia, o mar, a areia e o sol, os esportes invadem o cotidiano da cidade. Os primeiros clubes náuticos surgem unindo essas duas tendências. Uma relação muito fértil que muda, pouco a pouco, a rotina e a sociabilidade de uma cidade em constante expansão.

\section{REFERÊNCIAS}

ALENCAR, Edigar de. Fortaleza de ontem e anteontem. Fortaleza: Edições UFC/PMG, 1980.

ALMANACH DO ESTADO DO CEARÁ. Fortaleza, 1920, 1921, 1922, 1924, 1935.

ALMEIDA, Jane Maria Fernandes de; LIMA, Hermano Machado Ferreira.O Ensino Normal No Ceará No Governo Justiniano De Serpa (1922-1924). Cadernos De Cultura e Ciência, v. 1, p. 39-55, 2009.

ALMEIDA, Luciana Andrade de. Os sentidos das aparências: invenção do corpo feminino em Fortaleza (1900-1959). 2016. 369f. Tese (Doutorado em História) - Pontifícia Universidade Católica de São Paulo, São Paulo, 2016.

CEARÁ ILLUSTRADO. Fortaleza, n.27. 11 jan./1925.

CEARÁ ILLUSTRADO. Fortaleza, N.51. 28 jun.1925.

CEARÁ ILLUSTRADO. Fortaleza, N.52. 05 jul.1925.

CORREIO DO CEARÁ. Fortaleza, 11jul.1930.

CORREIO DO CEARÁ. Fortaleza, 28/ jul.1930.

CORREIO DO CEARÁ. Fortaleza, 03abr. 1933.

CORREIO DO CEARÁ, Fortaleza, 16 jul.1934

CORREIO DO CEARÁ. Fortaleza, 19 dez.1939.

CORREIO DO CEARÁ. Fortaleza, 02 mar.1942

CORREIO DO CEARÁ. Fortaleza, 21 fev.1943.

FREITAS, Gustavo da Silva. Práticas de divertimento no Cassino/RS em meados do século XX: a produção de um outro espaço no encontro com os infames. 2014. 141f. Tese (Doutorado em Educação em Ciências) - Universidade Federal do Rio Grande/FURG, Rio Grande, 2014. 
GIRÃO, Aluísio Barroso. Crônicas de outros tempos e de agora. Fortaleza: ABC Fortaleza, 1998.

JORNAL DO CEARÁ, Fortaleza, 07 abr.1905

JORNAL DO CEARÁ. Fortaleza, 07abr.1907.

JORNAL DO CEARÁ. Fortaleza, 19abr.1907.

KIRK, David. Physical Education Futures. New York: Routledge, 2010.

KIRK, David. Physical culture, Physical education and relational analysis. Sport, education and society, v. 4, n. 1 p. 63-73, 1999.

LUCA, Tania Regina de. História dos, nos e por meio dos periódicos. In: PINSKY, Carla Bassanezi. Fontes Históricas. 2. ed. São Paulo: Contexto, 2006. Páginas do capítulo? p. 111153

MATOS, Fábio de Oliveira. A cidade de papel: cartografia e fotografia na formação do espaço litorâneo de Fortaleza. 2009. 210 f. Dissertação (mestrado) - Universidade Estadual do Ceará, Centro de Ciências e Tecnologia, Fortaleza, 2009.

MONTENEGRO, Nara Romero. A praia reabitada: a invenção do divertimento litorâneo em Fortaleza (1900-1930). Trabalho de Conclusão de Curso. (Licenciatura-Educação Física) Faculdade de Educação Física UNICAMP. Campinas, SP, 2016.

NEVES, Frederico de Castro. Caridade e controle social na Primeira República (Fortaleza, 1915). Estudos Históricos, v. 27, n. 53, p. 115-133, jan./jun.2014.

O'DONNELL, Julia. A invenção de Copacabana: culturas urbanas e estilos de vida no Rio de Janeiro (1840-1940). Rio de Janeiro: Zahar, 2013.

O NORDESTE. Fortaleza, 12 ago.1939.

O NORDESTE. Fortaleza, 14 ago.1939.

O POVO. Fortaleza, 12 jun. 1929.

O POVO. Fortaleza, 14 out.1931.

PONTE, Sebastião Rogério. Fortaleza Belle Époque: reformas urbanas e controle social (18601930). Fortaleza: Fundação Demócrito Rocha/Multigraf, 1993.

REGGIANI, Andrés; SCHARAGRODSKY, Pablo. Circulación, difusión y apropiación de saberes y prácticas corporales: el caso de la gimnasia 'femenina' de Ruth Schwarz de Morgenroth (19351945). In. SCHARAGRODSKY, Pablo (comp). Mujeres en Movimiento. Deporte, cultura física y feminidades. Argentina, 1870-1980. Buenos Aires: Prometeo, 2016. p. 49-84.

SCHARAGRODSKY, Pablo. Introducción. In: SCHARAGRODSKY, Pablo. Miradas médicas sobre la 'cultura física' en Argentina (1880-1970). Buenos Aires: Editorial Prometeo, 2014. p. 9-12,

SCHARAGRODSKY, Pablo. Girls, Women and Physical Activity in Argentina. Past and present. THE INTERNATIONAL Council of Sport Science and Physical Education (ICSSPE). Bulletin. Journal of Sport Science and Physical Education No 72, PUBLISHER'S STATEMENT. 
Berlin, June 2017. Special Feature: Gender and Sport. Disponível em: https://www.academia. edu/35081592/_Girls Women and Physical_Activity in Argentina. Past and present. The International Council of Sport Science and Physical Education ICSSPE Acesso em: 28 out. 2018.

SCHOSSLER, Joana Carolina. História do veraneio no Rio Grande do Sul. Jundiaí, SP: Paco, 2013.

SCHRAMM, Solange Maria de Oliveira. Território livre de Iracema: só o nome ficou? Memórias coletivas e a produção do Espaço na Praia de Iracema. 2001. 176f. Dissertação (mestrado) Universidade Federal do Ceará, Centro de Humanidades, Fortaleza, 2001.

SILVA FILHO, Antonio Luiz Macêdo de. Fortaleza: imagens da cidade. Fortaleza: Museu do Ceará, Secretaria da Cultura e Desporto do Estado do Ceará, 2001.

TERRA, Vinicius. A invenção da praia de Santos (1880 - 1940). In: SOARES, Carmen Lúcia. Uma educação pela natureza: a vida ao ar livre, o corpo e a ordem urbana. Campinas: Autores Associados, 2016. p. 205-238.

VIGARELLO, Georges. Le corps redressé: histoired'un pouvoir pédagogique. Paris: JeanPierre Delarge, 1978.

Apoio:

FAPESP e do CNPq-Bolsa de Produtividade 